\title{
Comparative study on the volatile compounds and sensory characteristics of some locally produced potato chips
}

\author{
M. A. Mohamed ${ }^{1}$, M. I. Mohamed ${ }^{1}$, H. H. Fadel ${ }^{2}$ and S. M. Ghanem ${ }^{1 *}$ \\ ${ }^{1}$ Food Science and Technology Department, Faculty of Agriculture, Al-Azhar University, Cairo, Egypt \\ ${ }^{2}$ National Research Center, Flavour and Aromatic Chemistry Department, Dokki, Giza, Egypt \\ ${ }^{*}$ Corresponding author E-mail: sameh.ghanem@azhar.edu.eg (S. Ghanem)
}

\begin{abstract}
This study was carried out to evaluate the volatile compounds in the headspace of two types of fried potato chips (A and B), flavoured with salt only. The impact of seasoning addition (tomato, onion and cheese) that are highly preferred by consumers on the flavour quality of these two potato snacks was investigated. A comparative study concerning fat contents, headspace volatiles and sensory characteristics was carried out between the two brand types of tested potato chips. The results indicated that the lipid content of the two brand types of potato chips ranged from 28.65 to $33.41 \%$ in all tested traditional potato chips. The gas chromatography-mass spectrometric (GC-MS) analysis of the headspace volatiles of all samples revealed the presence of 86 volatile compounds with total higher content in all brand B varieties than brand A. The identified compounds included different chemical groups such as; sugar and Maillard degradation products, lipid degradation products, sulfur containing compounds, terpenes and miscellanies compounds. The total amount of lipid degradation products in samples A and B was lower than that of Maillard reaction, sugar degradation, or both products. The results revealed that sample As showed higher scores for all investigated attributes compared to sample $B_{s}$. The odour intensity and onion flavour scored higher values in sample $A_{\text {co }}$ than sample $B_{c o}$. Whereas, the taste attribute and cheese flavour showed the opposite trend. Concerning the tomato seasoned potato chips, sample $\mathrm{B}_{\mathrm{t}}$ showed higher scores for all investigated sensory attributes compared to sample At.
\end{abstract}

Keywords: potato chips, potato chips with salt, cheese and onion, tomato flavour, odour intensity.

\section{INTRODUCTION}

Potato (Solanum tuberosum L.) is one of the most important vegetable crops grown in Egypt. It is the fourth most important world crop after rice, wheat and maize. It is a major source of inexpensive energy. Moreover, potato is used in many industries, such as French fries, chips, starch and alcohol production (Elhakim et al., 2016).

In Egypt, potato chips are considered one of the most important products of food industry and they are the top choice for between-meal munching for adults and children (Allshouse et al., 2002). Potato crisp is a fragile but firm slice of potato that has been cooked by deep-frying in vegetable oil and to which edible salt (powder or brine) or permitted food grade spices, colour and flavour may have been added (Surkan et al., 2009; Godswill et al., 2018).

The potato chip or crisp is considered one of the most popular snacks globally (Dhital et al., 2018). Some authors define a snack as a portion of food, smaller than a regular meal, generally eaten between meals. Snack food manufacturers produce mainly two kinds of potato crisps: the traditional crisps from fresh potatoes, which are produced from thinly slicing and deep frying of them, and the typical restructured potato crisps from potato dough, which are molded into desired shapes by extruding or pressing before frying, such as Pringles (Pedreschi et al., 2018).

Traditionally, potato crisps are produced by oil frying to a temperature well above the boiling point of water $\left(180^{\circ} \mathrm{C}\right)$, causing evaporation of water inside the product, and the formation of a crust. Besides cooking foods very quickly, this unit operation also provides unique sensorial attributes attractive to the consumer, such as colours, aromas, flavours and textures that improve the overall palatability (Pedreschi et al., 2018).

Consumer's acceptance of food stuffs is closely related to their flavours. Volatiles from potato snacks are usually classified based on the mechanism of formation (Whitfield and Last, 1991; Comandini et al., 2011; Raigond et al., 2015). These volatiles are lipid oxidation products, Maillard, sugar degradation or all such products and small amounts of endogenous flavour compounds (Loon et al., 2005)

Chips flavour is affected by many factors including potato tuber composition, frying oil composition and temperature and the time of frying (Martin and Ames 2001). Studies on the 
volatile compounds of potato chips have been reviewed by Jansky (2010). More than 500 volatile compounds were identified in the volatiles of French fries and potato chips showing a similar aroma (Comandini et al, 2011). Among the 150 volatile compounds identified in the volatiles of potato chips, 60 compounds are lipid degradation products, with the polyunsaturated fatty acids of the frying oil likely to be their main precursors (Warner et al., 1997).

Flavour stability in seasoned snack food, such as potato chips, is of great importance because of its relationship with the quality and acceptability of foods over the shelf life but is often difficult to control. Cheese and onion seasoning helps in slowing the lipid oxidation in deep-fried potato crisps and consequently controls both the shelf-life stability of seasoning and seasoned products (Agarwal et al., 2018). Cheese flavour is one of the most important criteria determining consumer choice and acceptance (Avsar et al., 2004). Cheese flavouring agent, because of its rich flavours, convenient application, lower cost and long shelf life, is used in a variety of products including, by way of example only, breads, salad dressings, cheese spreads, pizza toppings, sauces and snack foods (El-Shayeb et al., 2017).

Tomato seasoned potato chips are very popular among consumers, however, no studies could be found regarding the impact of tomato flavour on the odour profile of potato chips. Flavour and aroma are essential parameters of quality in tomatoes. Characteristic tomato flavour results from taste components, aromatic volatiles and a complex interaction between them (Yilmaz 2001). Among over 400 volatile compounds determined in tomatoes, only a limited number is considered essential to the aromatic component of tomato flavour. Volatiles in fresh tomatoes and leaves are formed from lipids, carotenoids, amino acids, terpenoids (C10 and C15), lignin and other sources. The pleasant sweet-sour taste of tomatoes is mainly due to their sugars (primarily the reducing sugars, glucose and fructose) and organic acids (citric and malic acids) are the major organic acids content (Tandon et al., 2000).

Flavour analysis using a variety of methods has been conducted for many years to help the development of new products, to understand the nature of existing products, to study shelflife, and to maintain quality of foods, beverages, products for oral care, and other products such as oral pharmaceuticals and tobacco (Meilgaard et al., 2006; Lawless and Heymann, 2010).
Flavour evaluation is usually carried out by sensory and/or instrumental analysis. Sensory descriptive tests involve the detection and description of both qualitative and quantitative sensory components of a product by trained panels. Descriptive tests can establish a relationship between sensory and instrumental results (Comandini et al., 2011). An important factor affecting consumer preferences of a fried food is its flavour which is defined as the combined perception of aroma, taste and mouthfeel sensation (Montaser et al., 2017). However, sensory methods are sometimes expensive to implement, may be timeconsuming when used properly, and sometimes cannot be implemented "on-line" for immediate feedback.

Instrumental methods for examining flavour have also been developed to provide feedback about the individual compounds associated with flavours. Those methods take many forms, but all are based on separation, identification, and quantification of compounds either in headspace or the actual product matrix (Maarse, 1991). The analysis of volatile compounds in food is commonly performed using gas chromatographic (GC) techniques, employing very sensitive technologies capable of detecting trace levels of volatile compounds. It is fundamental that GC detection has high efficiency, especially for volatile compounds, present at trace levels, can be easily perceived during sensory analysis (low perception threshold) and can contribute significantly to the flavour profile of cheese (Hummel et al., 1997).

The aim of the present work is to compare the volatile profile of two potato chip brands that are highly popular locally among Egyptian consumers, especially for children. The study was extended to evaluate the impact of seasoning addition (tomato, onion and cheese) on the headspace volatiles and sensory qualities of these two potato snacks. The oil content of each sample was determined, due to its effect on the overall quality of potato chips flavour.

\section{MATERIALS AND METHODS}

\section{Materials}

\section{Potato chips samples}

The manufactured potato chips samples (which represent of the most common brands distributed in the Egyptian local markets) were collected from the most frequently consumed brands (different producers, A and B); for each brand, three varieties of potato chips were chosen (unseasoned, seasoned with cheese \& 
onion and tomato). These potato chips represent a major portion of the potato chip products processed in the Arab Republic of Egypt.

All potato chips samples (manufactured at same date) were purchased from local market. The samples, packed in plastic bags, were transported to the laboratory until analyses. The code number of each tested potato chips sample was shown in Table (1).

\section{Ingredients of tested potato chips}

The basic composition of the investigated samples is fresh potato, vegetable oil and food additive such as some flavouring agents.

Authentic compounds and standard nparaffin (C8-C20) were purchased from SigmaAldrich CO. (St. Louis, MN, USA) and Merck (Darmstadt, Germany), respectively. All other chemicals were analytical grade.

\section{Methods}

\section{Preparation of tested samples}

The different potato chips samples were crushed in a mill cup blender and made homogeneous, then subjected to oil extraction, sensory analysis, isolation and identification of headspace volatiles.

\section{Determination of lipid content (\%)}

Fat content was determined by extracting a weighed sample of $10 \mathrm{~g}$ with petroleum ether (boiling point $60-80^{\circ} \mathrm{C}$ ) in a Soxhlet apparatus for $16 \mathrm{~h}$. The extract containing lipid and petroleum ether was evaporated over steam bath and dried in an oven at low temperature $\left(50{ }^{\circ} \mathrm{C}\right)$, weighed and lipid percent was calculated according to the method described by AOAC (2011).

\section{Analysis of volatile compounds by Gas chromatography / mass spectrometry}

\section{Extraction of volatile compounds}

About $100 \mathrm{~g}$ of tested potato chips samples were placed in a conical flask containing $500 \mathrm{ml}$ distilled water. The mixture solution was stirred using teflon-coated magnetic bar at 60 ${ }^{\circ} \mathrm{C}$. The volatiles were purged with purified nitrogen (grade of $\mathrm{N}_{2}>99.99 \%$ ), at flow rate $100 \mathrm{ml} / \mathrm{min}$ for $5 \mathrm{~h}$ to three cooling traps at low temperature (ice - water/ice - acetone/dry ice acetone). Volatile chemicals collected in each trap were recovered with diethyl ether pentane $(1: 1, \mathrm{~V} / \mathrm{v})$. The solvents containing volatiles were dried over anhydrous sodium sulphate for $12 \mathrm{~h}$ and concentrated with a
Vigreux column $(25 \mathrm{~cm})$ to final volume of 100 $\mu 1$. (Fadel et al., 2006).

\section{Characterization of volatile compounds by GC/ MS analysis}

The analysis was carried out by using a coupled gas chromatography Hewllet-Packard (5890)/ mass spectrometry Hewllet-Packard (5890), (Bremen, Germany). A fused silica capillary column DB5 (60 $\mathrm{m} \times 0.32 \mathrm{~mm}$ i.d.) was used. The oven temperature was maintained initially at $50{ }^{\circ} \mathrm{C}$ for $5 \mathrm{~min}$, then programmed from 50 to $250{ }^{\circ} \mathrm{C}$ at a rate of $4{ }^{\circ} \mathrm{C} / \mathrm{min}$. Helium was used as the carrier gas at a flow rate of 1.1 $\mathrm{ml} / \mathrm{min}$. The injector and detector temperatures were 220 and $250{ }^{\circ} \mathrm{C}$, respectively. The mass spectrometry was operated in electron impact mode (EI) 70.ev, mass range $m / z$ 39-400 amu. The retention indices (Kovats index) of the separated volatile components were calculated with hydrocarbon (C8-C20, Aldrich Chemical CO.) as references. The isolated peaks were identified by matching with data from the library of mass spectra (NIST) (version 2.0) and comparison with those of authentic compounds and published data (Adams, 1995). The amount of each individual compound was expressed as total ion chromatogram (TIC).

\section{Sensory analysis of tested potato chips}

Sensory analysis was aimed to monitor the differences in sensory attributes between the investigated potato chips A and B regarding each type (Table 1). Sensory evaluation was carried out according to Majcher and Jeleń (2005) with some modifications. In the present study, each type of potato chips brand A was compared to the same type of brand $B$, such as: $\mathrm{A}_{\mathrm{s}}$ compared with $\mathrm{B}_{\mathrm{s}}$, $\mathrm{A}_{\mathrm{co}}$ compared with $\mathrm{B}_{\mathrm{co}}$ and At compared with Bt. Ten panelists were drawn from the Chemistry of Flavour and Aroma Department, National Research Center and Food Science and Technology Department, Faculty of Agriculture, Al-Azhar University. All were requested to evaluate the sensory attributes to determine the acceptability of the samples regarding odour, taste, seasoning perception such as salt, cheese \& onion, tomato and overall acceptability. The individual panelists separately scored each attribute on a category scale 0.0 (not perceptible) to 10.0 (strongly perceptible). The analysis was carried out in triplicate.

\section{Statistical analysis}

The data were statistically analyzed by using the Statistical Package for Social Science (SPSS) computer program software; (version 20.0 produced by IBM Software, Inc., Chicago, 
USA) of a completely randomized design as described by Gomez and Gomez (1984). All obtained results are expressed as mean \pm standard error (SE). The statistical analysis was performed using a one-way analysis of variance (ANOVA) followed by Duncan's multiple range tests according to the procedure of Armitage (1971).

\section{RESULTS AND DISCUSSION}

Fat content is one of the most important parameters checked during the quality control processes. It affects the product's texture. The factors that influence fat uptake include: the quality of the raw material, the type of oil fraction and the technological process, with temperature and frying time being the two main parameters (Mazurek et al., 2016).

The lipid content of the two brand types of tested potato chips is listed in Table (2). The lipid content ranged from 28.65 to $33.41 \%$ in all tested potato chips with and without different flavouring agents. However, in the two brands, the seasoned samples showed higher oil content compared with the unseasoned samples.

The present results revealed that for all tested samples the oil content was lower than the recommended value (within the permissible values $\geq 42 \%$ ), reported by the Egyptian Standard Specifications (2005), of potato chips. On the other side, the lipid content in tested potato chips brand B with salt only and also with cheese and tomato flavours was more than that found in tested potato chips brand A. Furthermore, the lipid content in both tested samples brands A (28.65\%) and B (31.70\%) with salt was lower than those obtained in flavoured tested samples, which recorded 30.45 and 31.92 $\%$ of tested samples of brand A, 33.28 and $33.41 \%$ of tested samples brand of B with cheese and tomato flavours; respectively. These results are consistent with the findings of Minihane and Harland (2007), Pedreschi et al. (2012), Mazurek et al. (2016), kalnina et al. (2017) and Caetano et al. (2018) who reported that the fried potato chips contain rather high amounts of fat (35-40\%). These results may be due to the moisture loss during deep-fat frying that results in oil uptake, which may amount to as much as $40 \%$ of total product weight (Pedreschi et al., 2012).

\section{Volatile compounds identified in fried potato chips seasoned with salt only}

As shown in Table (3), the total amount of volatile compounds in sample B were 2.72 folds higher than in sample $A$. The increase in the total amount of the volatile compounds in sample B compared with sample A may be due to several factors; (i) the higher oil content in $\mathrm{B}$ than A (Table 2); (ii) the sinuous surface of sample B may increase the amount of loaded volatile compounds; (iii) different frying condition and different potato varieties.

A total of 57 volatile compounds were identified in the two samples ( $A_{s}$ and $B_{s}$ ) (Table $3)$. These compounds were classified into five main chemical groups; lipid degradation products, sugar degradation and/or Maillard reaction products (not involving sulfurcontaining amino acids), sulfur-containing compounds, terpenes and miscellanies flavour compounds. Most of the identified compounds have been reported previously as volatiles from fried potato chips (Loon et al., 2005; Comandini et al., 2011).

\section{Sugar degradation and Maillard reaction products}

The aroma compounds produced by Maillard reaction and/or sugar degradation products included: Strecker aldehydes (4), diketones (2), pyrazines (6), furans (4), acetic acid and ethyl pyrrole (Table 3).

The total ion chromatograms (TIC) of these chemical classes were $26.57 \times 10^{6}$ and $69.36 \times 10^{6}$ in the two samples $A_{s}$ and $B_{s}$, respectively. Approximately $85.6 \%$ of the aroma compounds identified in head space volatiles of Frenchfried potato chips were generated from sugar degradation and/or Maillard reaction, not involving sulfur-containing compounds (Loon et al., 2005; Cha et al., 2019).

The di ketones 2,3- butandione (1) and 2,3pentandione (10) are sugar degradation products and contribute to caramel and buttery note. They were identified among the active compounds from French fries (Loon et al., 2005).

2-Methyl butanal (6), 3-methyl butanal (7), phenylacetaldehyde (46) and benzaldehyde (33) are strecker aldehydes of the amino acids; isoleucine, leucine and phenylalanine, respectively (Martin and Ames, 2001a). Their major formation pathway seems to be oxidative deamination-decarboxylation of the corresponding amino acids via strecker degradation (Sanches-Silva et al., 2005). Whereas, benzaldehyde (33) is produced by interaction of sugar with phenylalanine (Fong and Yaylayan 2008).

Compared to the previous studies, the total yield of 2-methyl butanal and 3-methyl butanal showed a relatively lower level $\left(3.13 \times 10^{6}\right.$ and 16. $\left.44 \times 10^{6}\right)$ in sample A and B; respectively. 
These two compounds were the predominant compounds in the volatiles of fried potatoes (Loon et al., 2005) and accounted for $81 \%$ of the total volatiles. Their low presentation in this study may be attributed to their oxidation to 2methyl butanoic acid (25) and 3- methyl butanoic acid (26), respectively (Loon et al., 2005), which were represented at high content $\left(7.92 \times 10^{6}\right.$ and $\left.15.56 \times 10^{6}\right)$ in the volatile of sample A and B, respectively. Compounds (25 and 26) do not seem to give a distinct note but may influence the perceived aroma as a whole.

The seven identified pyrazines were: 2methyl pyrazine (20), 2,5- dimethyl pyrazine (29), 2,3- dimethyl pyrazine (30), vinyl pyrazine (31), 2- ethyl-3-methyl pyrazine (40), 2- vinyl -6pyrazine methyl (41) and 3-ethyl -2,5-dimethyl pyrazine (47) (Table 3). Pyrazines are typical products of Maillard reaction (Corrales et al., 2017; Yu et al., 2019). Generally, they are associated with positive sensory perception in deep-fried potato crisps such as nutty, brown, roasted and baked, but also associated with a negative sensory perception such as raw and musty (Agarwal et al., 2018). Pyrazines are mainly formed from glutamine and asparagine, the most abundant amino acids in potatoes (Dresow and Böhm, 2009; Krishnakumar and Visvanathan, 2014).

2- Methyl pyrazine (20) was the major identified compound in sample $A_{s}\left(6.94 \times 10^{6}\right)$ and it showed approximately similar amount $\left(6.88 \times 10^{6}\right)$ in sample Bs. 2,5-dimethyl pyrazine (29) and 2- ethyl-3-methyl pyrazine (40) comprised $5.77 \times 10^{6}$ and $5.42 \times 10^{6}$ in sample $\mathrm{B}_{\mathrm{s}}$, respectively whereas, they showed less amounts $\left(1.87 \times 10^{6}\right.$ and $\left.1.60 \times 10^{6}\right)$ in samples As. These compounds were the predominant pyrazines identified in the volatiles of potato chips fried in palmolein (Martin and Ames, 2001).

The five furans identified in the present study were vinyl furan (11), dihydro-2-methyl (2H)-furanone (18), 2-furfural (21) 5- methyl -2furfural (35) and 4- hydro -3,5-dimethyl $-3(2 \mathrm{H})$ furanone (48), with total amounts of $1.98 \times 10^{6}$ and $6.64 \times 10^{6}$ in sample $A$ and $B$, respectively (Table 3). 2-Furfural (21) is a typical sugar degradation product, and it possesses a pungent sweet note. 4-Hydro-3-5-dimethyl -3 (2H)- furanone (furaneol) (48) is formed via Maillard reaction from 2- hydroxyl propanal, and its oxidation product is 2- oxopropanal (Belitz et al., 2004).

\section{Lipid degradation products}

During frying, the hydroperoxides are formed as primary products of lipid oxidation.
These products are unstable and decompose to secondary oxidation products. Deep fat frying causes evaporation of water, which moves away from food into the surrounding oil that replaces some of the lost water. This process leads to a product with extremely high-fat content (Moreira et al., 1995; Nayak et al., 2016).

However, as shown in Table (3), the total amounts of lipid degradation products in samples A and B $\left(15.70 \times 10^{6}\right.$ and $47.48 \times 10^{6}$ respectively) were lower than that of Maillard reaction and/or sugar degradation products $\left(26.57 \times 10^{6}\right.$ and $\left.69.36 \times 10^{6}\right)$. This finding may be attributed to that the heat transfer from oil to the products is more favorable for sugar degradation and/or Maillard reaction than for lipid oxidation (Loon et al., 2005). At the same time, the melanodines formed from Maillard reactions are known to have an anti-oxidative effect (Morales and Jiménez-Pérez, 2001) and subsequently affect lipid oxidation.

The lipid-derived volatile compounds are corresponding to different chemical classes, aldehydes (9), ketone (2), alcohols (3), carboxylic acid (3), esters (3), furans (3) and hydrocarbons (2) (Table 3). These compounds are considered as secondary oxidation markers for lipid oxidation.

Among the nine aldehydes, hexanal (15) was the abundant compound in sample $B$ $\left(15.76 \times 10^{6}\right)$ whereas; it showed much less amount $\left(2.00 \times 10^{6}\right)$ in sample A. It is a typical oxidation product of lineoleic acid and used as a marker of lipid oxidation (Sanches- Silva et al., 2005 and Comandini et al., 2011).

The amount of nonanal (52) in sample B $\left(1.12 \times 10^{6}\right)$ was three and half fold higher than its amount in sample A $\left(0.31 \times 10^{6}\right)$. Hexanal and nonanal were detected at high concentrations in the volatiles of French fried potatoes (Loon et al., 2005). The first compound is the predominant degradation product of 2,4decadienal $(E, Z)$ (62) which is formed from linoleic acid (Hammond, 1993 and Diaz et al., 2015).

Loon et al. (2005) confirmed the fact that 2,4decadienal (E,Z) (62), 2,4- decadienal (E,E) (63) and 2,4 (E,E) nonadienal (57) contribute to the deep-fried note. These compounds were identified as the main volatile compounds in palmolein fried potato chips (Comandini et al., 2011).

The two identified ketones, 3-heptanone (24) and octenal (39) are oxidative degradation products of unsaturated fatty acids (Careri et al., 
1994). They were identified among the volatiles of potato crisps (Sanches-silva et al., 2005).

Three alcohols, 1-octen -3-ol (36), dodecanol (76) and tetradecanol (84) are shown in Table (3), with total amount $2.30 \times 10^{6}$ and $1.94 \times 10^{6}$ in samples A and B, respectively. They have a minor significant role in flavour of fried potatoes. The three identified carboxylic acids are hexanoic acid (37), decanoic acid (68) and dodecanoic acid (81). They are formed by lipid oxidation or by deamination of amino acids during the frying process. Therefore, their high presentation indicates the advanced lipid oxidation state (Sanches- Silva et al., 2005).

The three identified esters, ethyl decanoate (69), methyl dodecanoate (78) and ethyl dodecanoate (82), accounted for $0.82 \times 10^{6}$ and $0.52 \times 10^{6}$ in sample A and B, respectively. These compounds are esterification products of carboxylic acid and alcohols (Guillén et al., 2004).

The lipid degradation furans reported in Table (3) are methyl furan (2), tetrahydrofuran (3), 2- ethyl furan (9) and pentyl furan (38). 1octen-3-ol and 2-pentyl furan are degradation products of linoleic acid and are responsible for fatty and fruity notes (Neff et al., 2000).

\section{Sulfur-containing compounds}

The total yield of the three identified sulfur compounds, 1,2 dimethyl disulfide (12), methional (28) and dimethyltrisulfide (34), showed low representation in both samples A and $\mathrm{B}\left(0.97 \times 10^{6}\right.$ and $2.95 \times 10^{6}$, respectively). These compounds are Maillard reaction products and characterized as sulfuryl and onion flavour (Loon et al., 2005). These compounds comprised low amount of the total volatiles of French fries (Loon et al., 2005). Methional, a strecker aldehyde of methionine, is a potent odorant of French fries flavour (Wagner and Grosch, 1997; Majcher and Jeleń, 2005). The low amount of methional might be due to its masking by 2,5 - di methyl pyrazine (Oruna-Concha et al., 2001).

\section{Miscellanies compounds}

Styrene (27) is a benzene derivative that contributes to the sweet and balsamic aroma note (Zhang et al., 2020 and Corrales et al., 2017). It is naturally synthesized by several plant species (Fernandez et al., 2005) and significantly increased at high temperatures. It was found in the headspace volatiles of fried potatoes (Loon et al., 2005). Limonene (42) was detected in the volatiles of French fries (Loon et al., 2005). 2Isobutyl-2-methoxy pyrazine (54) was detected in the volatiles of raw and boiled potato. $\beta$ - damascenone (E) (70) was reported as a degradation product of carotenoids (Majcher and Jeleń, 2005). It is present in raw foods, and its amount increases during different heat processing.

Volatile compounds identified in headspace of fried potato chips seasoned with cheese and onion

A total of 55 volatile compounds were classified into five main chemical groups; Maillard reaction and sugar degradation products, lipid degradation products, sulfurcontaining compounds, terpenes and miscellanies compounds.

As shown for potato chips seasoned with salt only (Table 3 ), the total volatiles in sample $\mathrm{B}_{\mathrm{s}}\left(124.48 \times 10^{6}\right)$ were higher than in sample $\mathrm{As}_{\mathrm{s}}$ $\left(47.74 \times 10^{6}\right)$. Most of the identified compounds were previously identified in headspace of potato chips seasoned with salt only (Table 3 ). Some of the volatile compounds reported in Table (3) are specific aroma compounds of onion and cheese. Butandione (1) was represented by $1.16 \times 10^{6}$ and $1.20 \times 10^{6}$ TIC in sample $A_{c o}$ and $B_{c o}$ respectively. This compound possesses buttery note (Avsar $e t$ al., 2004) and reported as an active aroma compound in cheddar and Swiss cheeses (Castada et al., 2019).

The identified acids; acetic acid (5), butanoic acid (16), 3- methyl butanoic acid (26), haxanoic acid (37), dedcanoic acid (68) and dodecanoic acid (81) were found in the volatiles of different cheese types (Avsar et al., 2004 and Hayaloglu and Karabulut, 2013). Acetic acid and butanoic acid are produced by lipolysis or by fermentation of lactose or lactic acids whereas, 3- methyl butanoic acid is produced by metabolism of leucien (Curioni et al., 2002). Compounds 16 and 37 are the principal acids in Turkish cheese (Hayaloglu and Karabulut, 2013). Their importance is due to their low perception thresholds as well as the fact that they are precursors for the formation of methyl ketones, alcohols, lactones and esters (Pinho et al., 2004).

As shown in Table (3), 3-methyl butanoic acid (26) was the major compound identified in headspace of the two samples $A$ and $B$ $\left(10.86 \times 10^{6}\right.$ and $20.82 \times 10^{6}$, respectively). This compound is produced from the oxidation of 3methyl butanal (McSweeney and Sousa 2000; Castada et al., 2015). The aldehydes reported in Table (3) are produced by catabolism of fatty acids or amino acids via decarboxylation or deamination (McSweeney and Sousa 2000). 
Hexanal (15), a lipid degradation product, was the predominant aldehyde in sample Aco and $\mathrm{B}_{\mathrm{co}}$ (5.36 and $8.22 \times 10^{6}$, respectively). 2Methylbutanal (6) and 3-methylbutanal (7), strecker aldehydes of isoleucine and leucine, accounted for 0.0 and $2.80 \times 10^{6}$ in sample $A_{c o}$ and 0.80 and $2.28 \times 10^{6}$, respectively in sample

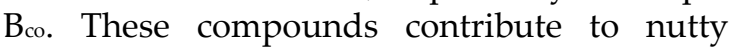
flavour in aged cheddar cheese (Avsar et al., 2004; Whetstine et al., 2006). 3-Methylbutanal (6), hexanal (15) and pentanal (14) were the predominant aldehydes identified in Turkish cheese (Hayaloglu and Karabulut, 2013). Aldehydes are transitory compounds and do not accumulate significantly in cheese as they rapidly transform into alcohols and corresponding acids (Bovolenta et al., 2014). A strong negative correlation was found between 3- methyl butanoic acid and 3- methyl butanal (McSweeney and Sousa 2000; Castada et al., 2015).

Six sulphides were identified and reported in Table (3) such as methional (28), methyl-1propenyl disulfide (32), dimethyl trisulfide (34), iso propely propyl disulfide (44), dipropyl disulfide (51) and dipropyl trisulfide (76), with total amount of $7.45 \times 10^{6}$ and $15.80 \times 10^{6}$ in sample $A_{c o}$ and $B_{c o}$, respectively. Among these compounds, 32, 44, 51 and 67 are generally associated with onion sensory perception (Villière et al., 2015).

Limonene (42), the only terpene identified in the present study, comprised 0.40 and $1.79 \times 10^{6}$ in sample $A_{c o}$ and $B_{c o}$, respectively (Table 3 ). This compound was the most abundant terpene identified in Turkish cheese and it is associated with citrus like note (Nogueira et al., 2005). Limonene, dipropyl disulfide, dimethyl trisulfide, methyl-1-propenyl disulfide, isopropyl propyl disulfide and 3methylbutanal were identified with cheese and onion seasoned potato crisps as specific compounds (Agarwal et al., 2018).

\section{Volatile compounds identified in headspace of tomato seasoned potato chips}

A total of 41 volatile compounds were identified in headspace of the two potato chips samples $\left(\mathrm{A}_{t}\right.$ and $\mathrm{B}_{\mathrm{t}}$ ) seasoned with tomato flavour. The identified compounds were classified into five main chemical classes; sugar degradation and Maillard reaction products, lipid degradation products, sulfur containing compounds, terpenes and miscellanies compounds.

Among the identified compounds, several compounds are considered as key odorants of tomato aroma. As previously mentioned, the total volatiles of sample B were higher than that in sample A (Table 3). 3--Methyl butanal (7), hexanal (15), hexanol (23), hexanoic acid (37), nonanoic acid (58), 2-decanal (59), (E,Z) 2,4 decadienal (62), (E, E)-2,4-decadienal (63), dedcanoic acid (68), dodecanoic acid (81), methional (28), limonene (42), isobutyl thiazole (45), guaiacol (49), 2- phenyl alcohol (50), methyl salicylate (55) $\alpha$-terpineol (56), geranial (60), geraneol (61), eugenol (64), geranyl acetone (73) and $\beta$-Ionone (77) were reported as important tomato aroma compounds (Alonso et al., 2009; Güler and Şekerli, 2013; Selli et al., 2014). Isobutyl thiazole accounted for $3.86 \times 10^{6}$ and $4.85 \times 10^{6}$ in samples A and B, respectively and it was described as tomato leaves-like aroma (Alonso et al., 2009).

Cis-3- Hexanal (tomato leaf-like fresh, cut grass) is considered one of the most contributors to tomato aromas (Selli et al., 2014). The absence of this compound in the present study may be correlated to the extraction technique of volatile compounds. In a previous study (Alonso et al., 2009), cis-3- hexanal was found in simultaneous steam distillation extraction (SDE) and hydrodistillation (HD) of tomato flavour, but wasn't in solid phase microextraction (SPME). Hexanal accounted on 2.53x $10^{6}$ and $10.46 \times 10^{6}$ of the total volatiles of samples A and B, respectively (Table 3). It was the main compound in traditional tomatoes with abundance percentage in head space of around $40 \%$ of total volatiles (Alonso et al., 2009).

The peak area of 2. phenyl ethanol (floral) was found in quantities of 0.23 and $1.27 \times 10^{6}$ in the volatiles of samples A and B, respectively. It was previously detected by Tandon et al. (2001) as potent odorants in red-ripe stage tomatoes. Geranyl acetone (Lavender, fruity, and rose sweet aroma) (Alonso et al., 2009) is the main volatile compound from lycopene degradation in tomatoes (Krumbein et al., 2004).

$\beta$-Ionone is consistently present in tomato at all stages of ripening. It is oxidative breakdown product of $\beta$-carotene. Methyl salicylate was predominant volatile compound in green tomato (Güler and Sekerli, 2013).

\section{Sensory analysis of tested potato chips samples}

The Fig. ( $1 \mathrm{a}, \mathrm{b}$ and $\mathrm{c})$ shows the results of sensory analysis of the potato chips samples A and B seasoned with salt only, cheese and onion and tomato flavour. As illustrated in the obtained results in Fig. $(1 \mathrm{a})$, it is obvious that the salt seasoned potato chips brand A showed 
higher scores for all investigated sensory attributes compared to brand $\mathrm{B}$.

Regarding cheese and onion seasoned potato chips (Fig. b), the low score of the overall acceptability of sample $B_{\text {co }}$ compared with sample Aco, may be correlated to the unacceptable oily flavour detected by the panelists. The odour intensity and onion flavour scored higher in sample $A_{c o}$ than sample $\mathrm{B}_{\mathrm{co}}$. Whereas, the taste attribute and cheese flavour showed the opposite trend. Concerning the tomato seasoned potato chips, sample $B_{t}$ showed higher scores for all of the investigated attributes compared to sample $A_{t}$ (Fig. c).

\section{CONCLUSION}

In the present study two potato chips brands $\mathrm{A}$ and $\mathrm{B}$ which are the most acceptable to the Egyptian consumers were chosen and subjected to a comparative study concerning their flavour qualities. Three similar varieties of each brand were selected in this study such as unseasoned potato chips (salt only), cheese and onion seasoned potato chips and tomato seasoned potato chips. In general, the total content of the headspace volatiles of all sample varieties of potato chips B was higher than their similar varieties of potato chips A. A total of 86 volatile compounds were identified in the present study with higher concentration in B than A, especially for the most contributors to the characteristic aroma of each variety. The sensory evaluation revealed that the overall acceptability of potato chips A flavoured with salt $A_{s}$ and cheese and onion $A_{c o}$ scored higher values than potato chips $B_{s}$ and $B_{c o}$. While tomato seasoned potato chips scored higher for all investigated sensory attributes. These differences between the two potato chips brands may be correlated to the different oil content, potato tubers, and time and temperature of frying.

\section{REFERENCES}

AOAC, 2011. Official Methods of Analysis of AOAC International. $18^{\text {th }}$ ed Published by the AOAC. International (revised edition), Gaithersburg, Maryland, U.S.A.

Adams, R.P., 1995. Identification of essential oil components by gas chromatography/mass spectrometry. Allured publishing carol stream Illinois, USA.

Agarwal, D., Mui, L., Aldridge, E., Mottram, R., McKinney, J., Fisk, I.D., 2018. The impact of nitrogen gas flushing on the stability of seasonings: volatile compounds and sensory perception of cheese \& onion seasoned potato crisps. Food Funct., 9 (9), 4730-4741.
Allshouse, J., Frazao, B., Turpening, J., 2002. Are Americans turning away from lower fat salty snacks?. Food Rev. Int., 25 (3), 38-43.

Alonso, A., Vázquez-Araújo, L., García-Martínez, S., Ruiz, J.J., Carbonell-Barrachina, Á.A., 2009. Volatile compounds of traditional and virus-resistant breeding lines of Muchamiel tomatoes. Eur. Food Res. Technol., 230 (2), 315-323.

Armitage, P., 1971. Statistical Methods in Medical Research. Blackwell Scientific Publications, London.

Avsar,Y.K., Karagul-Yuceer, Y., Drake, M.A., Singh, T.K., Yoon, Y., Cadwallader, K.R., 2004. Characterization of nutty flavour in cheddar cheese. J. Dairy Sci., 87 (7), 1999-2010.

Belitz, H.D., Grosch, W., Schieberle, P., 2004. Aroma compounds. In: Food Chemistry (pp. 342-408). Springer, Berlin, Heidelberg. Germany.

Bovolenta, S., Romanzin, A., Corazzin, M., Spanghero, M., Aprea, E., Gasperi, F., Piasentier, E., 2014. Volatile compounds and sensory properties of Montasio cheese made from the milk of Simmental cows grazing on alpine pastures. J. Dairy Sci., 97 (12), 7373-7385.

Caetano, P.K., Mariano-nasser, F.A.D.C., MendonÇa, V.Z.D., Furlaneto, K.A., Daiuto, E.R., Vieites, R.L., 2018. Physicochemical and sensory characteristics of sweet potato chips undergoing different cooking methods. Food Sci. Technol., 38(3), 434-440.

Careri, M., Barbieri, G., Bolzoni, L., Mangia, A., Parolari, G., Spagnoli, S., Virgili, R., 1994. Study of the volatile fraction of Parmesan cheese. J. Agric. Food Chem., 42 (5), 1170-1176.

Castada, H.Z., Hanas, K., Barringer, S.A., 2019 Swiss cheese flavour variability based on correlations of volatile flavour compounds, descriptive sensory attributes, and consumer preference. Foods, 8 (2), 78-94.

Castada, H.Z., Harper, W.J., Barringer, S.A., 2015. Volatile organic compounds of a Swiss cheese slurry system with and without added reduced glutathione, compared with commercial Swiss cheese. Int. Dairy J., 49, 72-77.

Cha, J., Debnath, T., Lee, K.G., 2019. Analysis of $\alpha$-dicarbonyl compounds and volatiles formed in Maillard reaction model systems. Sci. Rep., 9 (1), 1-6.

Comandini, P., Cerretani, L., Blanda, G., Bendini, A., Toschi, T.G., 2011. Characterization of potato flavours: an overview of volatile profiles and analytical procedures. N. Benkeblia (Vol. Ed.), Potato V. Food, 5 (1), 1-14.

Corrales, C.V., Lebrun, M., Vaillant, F., Madec, M.N., Lortal, S., Pérez, A.M., Fliedel, G., 2017. Key odor and physicochemical characteristics of raw and roasted jicaro seeds (Crescentia alata KHB). Food Res. Int., 96, 113-120.

Curioni, P.M.G., Bosset, J.O., 2002. Key odorants in various cheese types as determined by gas chromatographyolfactometry. Int. Dairy J., 12(12), 959-984.

Dhital, S., Baier, S.K., Gidley, M.J., Stokes, J.R., 2018. Microstructural properties of potato chips. Food Struct., 16, 17-26.

Diaz, J.M.R., Suuronen, J.P., Deegan, K.C., Serimaa, R., Tuorila, H., Jouppila, K., 2015. Physical and sensory characteristics of corn-based extruded snacks containing amaranth, quinoa and kañiwa flour. LWT-Food Sci. Technol., 64(2), 10471056. 
Dresow, J.F., Böhm, H., 2009. The influence of volatile compounds of the flavour of raw, boiled and baked potatoes: Impact of agricultural measures on the volatile components. Landbauforschung-vTI Agric. Forestry Res., 59 (4), 309-338.

Egyptian Standard Specifications. 2005. Edible oil for frying potato chips. Published by Egyptian Organization for Standardization and Quality Control, ARE.

Elhakim, S.A., El-Mesirry, D.S., Yousry, M.M., 2016. Impact of potassium fertilization rates and Bacillus circulans on the growth, yield and color of processed potato (Solanum tuberosum L.) tubers chips. Alex. Sci. Exch. J., 37: 594-605.

El-Shayeb, O.A., Saad, S.M., Sharoba, A.M., El-Hadary, A.E., 2017. Components extracted from product manufactured of tortilla chips and their raw materials. J. Biol. Chem. Environ. Sci., 12 (3), 131-156.

Fadel, H.H.M., Abdel Mageed, M.A., Abdel Samad, A.K.M.E., Lotfy, S.N., 2006. Cocoa substitute: evaluation of sensory qualities and flavour stability. Eur. Food Res. Technol., 223 (1), 125-131.

Fernandez, X., Lizzani-Cuvelier, L., Loiseau, A. M., Perichet, C., Delbecque, C., Arnaudo, J.F., 2005. Chemical composition of the essential oils from Turkish and Honduras Styrax. Flavour Fragr. J., 20 (1), 70-73.

Fong, C.L., Yaylayan, V.A., 2008. Model studies on the oxygeninduced formation of benzaldehyde from phenyl acetaldehyde using pyrolysis GC-MS and FTIR. J. Agric. Food Chem., 56 (22), 10697-10704.

Godswill, A.C., Amagwula, I.O., Victory, I.S., Gonzaga, A.I., 2018. Effects of repeated deep frying on refractive index and peroxide value of selected vegetable oils. Int. J. Adv. Acad. Res. Sci. Technol. Eng., 4 (4), 106-119.

Gomez, K.A., Gomez, A.A., 1984. Statistical Procedures for Agricultural Research $2^{\text {nd }}$ ed. John Wiley and Sons, New York, USA.

Guillén, M.D., Ibargoitia, M.L., Sopelana, P., Palencia, G., Fresno, M., 2004. Components detected by means of solidphase microextraction and gas chromatography/mass spectrometry in the headspace of artisan fresh goat cheese smoked by traditional methods. J. Dairy Sci., 87 (2), 284-299.

Güler, Z., Şekerli, Y.E., 2013. Distribution of volatile compounds in organic tomato (Lycopersicon esculentum) at different ripening stages. Acad. Food J., 11, 6-13.

Hammond, E.W., 1993. High performance liquid chromatography. Chromatography for the Analysis of Lipids, CRC Press, 113-153.

Hayaloglu, A.A., Karabulut, I., 2013. SPME/GC-MS characterization and comparison of volatiles of eleven varieties of Turkish cheeses. Int. J. Food Prop., 16 (7), 16301653.

Hummel, T., Sekinger, B., Wolf, S., Pauli, E., Kobal, G., 1997. 'Sniffin'sticks': olfactory performance assessed by the combined testing of odor identification, odor discrimination and olfactory threshold. Chem. Senses, 22, 39-52.

Jansky, S.H., 2010. Potato flavour. American J. Potato Res., 87 (2), 209-217.
Kalnina, I., Evita, S., Zanda, K., Martins, S., Tatjana, K., 2017. quality evaluation of potato and vegetable crisps in Latvian market. Res. Rural Dev., (1), 244- 250.

Krishnakumar, T., Visvanathan, R., 2014. Acrylamide in food products: a review. J. Food Process. Technol., 5 (7) 344.

Krumbein, A., Peters, P., Brückner, B., 2004. Flavour compounds and a quantitative descriptive analysis of tomatoes (Lycopersicon esculentum Mill.) of different cultivars in short-term storage. Postharvest Biol. Technol., 32(1), 15-28.

Lawless, H.T., Heymann, H., 2010. Sensory Evaluation of Foods: Principles and Practices, 2nd ed., Chapman \& Hall: New York, NY, USA, pp. 1-18 \& 125-148.

Loon, V.W.A., Linssen, J.P., Legger, A., Posthumus, M.A., Voragen, A.G., 2005. Identification and olfactometry of French fries flavour extracted at mouth conditions. Food Chem., 90 (3), 417-425.

Maarse, H., 1991. Introduction. In: Volatile Compounds in Foods and Beverages, $1^{\text {st }}$ ed.; Marcel Dekker Inc.: New York, NY, USA, pp. 1-39.

Majcher, M.A., Jeleń, H.H., 2005. Identification of potent odorants formed during the preparation of extruded potato snacks. J. Agric. Food Chem., 53 (16), 6432-6437.

Martin, F.L., Ames, J.M., 2001. Comparison of flavour compounds of potato chips fried in palmolein and silicone fluid. J. Am. Oil Chem. Soc., 78 (8), 863.

Martin, F.L., Ames, J.M., 2001a. Formation of Strecker aldehydes and pyrazines in a fried potato model system. J. Agric. Food Chem., 49 (8), 3885-3892.

Mazurek, S., Szostak, R., Kita, A., 2016. Application of infrared reflection and Raman spectroscopy for quantitative determination of fat in potato chips. J. Mol. Struct., 1126, 213-218.

McSweeney, P.L., Sousa, M.J., 2000, Biochemical pathways for the production of flavour compounds in cheeses during ripening: A review. Le Lait, 80 (3), 293-324.

Meilgaard, M., Civille, G.V., Carr, B.T., 2006. Advanced Statistical Methods. In: Sensory Evaluation Techniques. $4^{\text {th }}$ ed. CRC Press, Boca Raton, FL, USA.

Minihane, A.M., Harland, J.I., 2007. Impact of oil used by the frying industry on population fat intake. Crit. Rev. Food Sci. Nutr. , 47 (3), 287-297.

Mohamed, M.A., Saber, S.A., Assem, A.S., Gomaa, S.F, 2017. Effects of novel antioxidants composite on oxidative stability of refined, bleached, and deodorized palm olein during repeated deep frying of potato chips and sensory quality of final fried food. Int. J. Adv. Res. 5 (7), 1791-1796.

Morales, F.J., Jiménez-Pérez, S., 2001. Free radical scavenging capacity of Maillard reaction products as related to colour and fluorescence. Food Chem., 72 (1), 119-125.

Moreira, R., Palau, J., Sun, X., 1995. Simultaneous heat and mass transfer during the deep fat frying of tortilla chips. J. Food Process Eng., 18 (3), 307-320.

Nayak, P.K., Dash, U.M.A., Rayaguru, K., Krishnan, K.R., 2016. Physio-chemical changes during repeated frying of cooked oil: A Review. J. Food Biochem., 40 (3), 371-390.

Neff, W.E., Warner, K., Byrdwell, W.C., 2000. Odor significance of undesirable degradation compounds in heated triolein and trilinolein. J. Am. Oil Chem. Soc., 77 (12), 1303-1314. 
Nogueira, M.C.L., Lubachevsky, G., Rankin, S.A., 2005. A study of the volatile composition of Minas cheese. LWT-Food Sci. Technol., 38 (5), 555-563.

Oruna-Concha, M.J., Duckham, S.C., Ames, J.M., 2001. Comparison of volatile compounds isolated from the skin and flesh of four potato cultivars after baking. J. Agric. Food Chem., 49 (5), 2414-2421.

Pedreschi, F., Bunger, A., Skurtys, O., Allen, P., Rojas, X., 2012. Grading of potato chips according to their sensory quality determined by color. Food Bioprocess Tech., 5 (6), 24012408.

Pedreschi, F., Cortés, P., Mariotti, M.S., 2018. Potato crisps and snack foods. In: Reference Module in Food Science. Elsevier. pp. 1-10.

Pinho, O., Ferreira, I.M.P.L.V.O., Ferreira, M., 2004. Discriminate analysis of the volatile fraction from "Terrincho" ewe cheese: Correlation with flavour characteristics. Int. Dairy J., 14 (5), 455-464.

Raigond, P., Singh, B., Dhulia, A., Chopra, S., Dutt, S., 2015. Flavouring compounds in Indian potato snacks. J. Food Sci. Technol., 52(12), 8308-8314.

Sanches-Silva, A., Lopez-Hernández, J., Paseiro-Losada, P., 2005. Profiling flavour compounds of potato crisps during storage using solid-phase microextraction. J. Chromatogr. A, 1064 (2), 239-245.

Selli, S., Kelebek, H., Ayseli, M.T., Tokbas, H., 2014. Characterization of the most aroma-active compounds in cherry tomato by application of the aroma extract dilution analysis. Food Chem., 165, 540-546.

Surkan, S., Albani, O., Ramallo, L., 2009. Influence of storage conditions on sensory shelf life of yerba mate. J. Food Qual., 32 (1), 58-72.

Tandon, K.S., Baldwin, E.A., Shewfelt, R.L., 2000. Aroma perception of individual volatile compounds in fresh tomatoes (Lycopersicon esculentum, Mill.) as affected by the medium of evaluation. Postharvest Biol. Technol., 20 (3), 261-268.

Tandon, K.S., Baldwin, E.A., Goodner, K.L., Jorda, M., 2001. Characterization of fresh tomato aroma volatiles using GColfatometry. In: Proceedings of the annual meeting of the Florida State Horticultural Society. Florida State Horticultural Society. FL.

Villière, A., Le Roy, S., Fillonneau, C., Guillet, F., Falquerho, H., Boussely, S., Prost, C., 2015. Evaluation of aroma profile differences between sué, sautéed, and pan-fried onions using an innovative olfactometric approach. Flavour, 4 (1), 1-19.

Wagner, R., Grosch, W. 1997. Evaluation of Potent Odorants of French Fries. Lebensm.-Wiss. -Technol., 30, 164-169

Warner, K., Orr, P., Glynn, M., 1997. Effect of fatty acid composition of oils on flavour and stability of fried foods. J. Am. Oil Chem. Soc., 74 (4), 347-356.

Whetstine, M.C., Drake, M.A., Nelson, B.K., Barbano, D.M., 2006. Flavour profiles of full-fat and reduced-fat cheese and cheese fat made from aged cheddar with the fat removed using a novel process. J. Dairy Sci., 89 (2), 505-517.

Whitfield, F.B., Last, J.H. 1991. Vegetables. In: Volatile Compounds in Foods and Beverages, edited by H. Maarse. Marcel Dekker, New York, pp. 223-281.

Yilmaz, E., 2001. The chemistry of fresh tomato flavour. Turk. J. Agric. Forest., 25 (3), 149-155.

Yu, H., Seow, Y.X., Ong, P.K., Zhou, W., 2019. Effects of ultrasonic processing and oil type on Maillard reaction of D-glucose and 1-alanine in oil-in-water systems. Food Bioproc. Technol., 12 (2), 325-337.

Zhang, H., Chang, C., Wu, G., Jin, Q., Wang, X., 2020. Deep-fried flavour: characteristics, formation mechanisms, and influencing factors. Crit. Rev. Food Sci. Nutr., 60 (9), 14961514.

Table 1. The code numbers of tested potato chips samples.

\begin{tabular}{|c|c|c|}
\hline Brand code & Cod. No. & $\begin{array}{l}\text { Sample collected with different flavour } \\
\text { (Cod. Name) }\end{array}$ \\
\hline \multirow{3}{*}{ A } & $\mathrm{A}_{\mathrm{s}}$ & Salt \\
\hline & Aco & Seasoned cheese \&onion flavour \\
\hline & $A_{t}$ & Tomato flavour \\
\hline \multirow{3}{*}{ B } & $\mathrm{B}_{\mathrm{s}}$ & Salt \\
\hline & $\mathrm{B}_{\mathrm{co}}$ & Seasoned cheese \&onion flavour \\
\hline & $\mathrm{B}_{\mathrm{t}}$ & Tomato flavour \\
\hline
\end{tabular}

Table 2. lipid content (\%) of tested potato chips (Means \pm SE).

\begin{tabular}{clc}
\hline Potato chips samples & \multicolumn{2}{c}{ Lipid content (\%) } \\
\hline \multirow{2}{*}{ brand A } & Salt & $28.65 \pm 0.07^{\mathrm{c}}$ \\
& Seasoned cheese & $30.45 \pm 0.11^{\mathrm{b}}$ \\
& Tomato & $31.92 \pm 0.15^{\mathrm{ab}}$ \\
\multirow{2}{*}{ brand B } & Salt & $31.70 \pm 0.04^{\mathrm{ab}}$ \\
& Seasoned cheese & $33.28 \pm 0.08^{\mathrm{a}}$ \\
& Tomato & $33.41 \pm 0.11^{\mathrm{a}}$ \\
\hline
\end{tabular}

$\mathrm{a}, \mathrm{b}, \mathrm{c}$ Means in the same column with different superscripts are different significantly $(p<0.05)$ 
Table 3. Volatile compounds identified in headspace of different types of flavoured potato chips.

\begin{tabular}{|c|c|c|c|c|c|c|c|c|}
\hline \multirow{2}{*}{$\begin{array}{c}\text { Peak } \\
\text { No. }\end{array}$} & \multirow{2}{*}{ (K.I.) } & \multirow{2}{*}{ Compounds } & \multicolumn{6}{|c|}{ TIC (values $\times 10^{6}$ ) } \\
\hline & & & As & $\mathbf{B}_{\mathrm{s}}$ & Aco & Bco & $\mathbf{A}_{\mathbf{t}}$ & $\mathbf{B}_{\mathbf{t}}$ \\
\hline \multicolumn{9}{|c|}{ Sugar degradation and Maillard reaction products (not involving sulfur containing amino acids) } \\
\hline 1 & 610 & 2,3- Butandione & 0.46 & 4.84 & 1.16 & 1.20 & 0.27 & 1.09 \\
\hline 5 & 650 & Acetic acid & 0.15 & 1.73 & 0.28 & 0.80 & 0.26 & 1.07 \\
\hline 6 & 654 & 2-Methylbutanal & 1.52 & 3.68 & - & 0.80 & - & - \\
\hline 7 & 664 & 3-Methylbutanal & 1.61 & 12.76 & 2.80 & 2.28 & 1.66 & 5.39 \\
\hline 10 & 697 & 2,3Pentandione & 0.51 & 1.54 & - & - & - & - \\
\hline 11 & 713 & Vinyl furan & - & 0.40 & - & - & - & - \\
\hline 17 & 820 & 1- Ethyl pyrrole & 0.40 & 2.11 & 0.93 & 3.74 & - & - \\
\hline 18 & 822 & Dihydro-2-methyl(2H)-furanone & 1.06 & 1.26 & - & 2.31 & - & - \\
\hline 20 & 831 & 2-Methylpyrazine & 6.94 & 6.88 & 1.02 & 1.63 & 0.42 & 1.44 \\
\hline 21 & 834 & 2-Furfural & 0.39 & 3.90 & - & 0.11 & - & - \\
\hline 25 & 884 & 2-Methyl butanioc acid & 2.99 & - & 4.27 & 4.44 & - & - \\
\hline 26 & 888 & 3-Methyl butanioc acid & 4.93 & $15 . .56$ & 10.86 & 20.82 & 5.45 & 27.24 \\
\hline 29 & 911 & 2,5- Dimethyl-pyrazine & 1.87 & 5.77 & 4.06 & 8.09 & 2.25 & 9.94 \\
\hline 30 & 923 & 2,3- Dimethyl-pyrazine & - & 0.31 & - & 0.36 & - & - \\
\hline 31 & 943 & Vinyl pyrazine & 0.36 & 1.26 & 0.74 & 1.30 & 0.37 & 1.39 \\
\hline 33 & 969 & Benzaldehyde & 0.21 & 0.88 & 0.54 & 1.00 & 0.29 & 0.83 \\
\hline 35 & 978 & 5-Methyl-2- furfural & 0.19 & 1.08 & 0.85 & 0.93 & 0.48 & 0.85 \\
\hline 40 & 1005 & 2-Ethyl-3-methyl-pyrazine & 1.60 & 5.42 & 4.34 & 7.66 & 2.70 & 10.06 \\
\hline 41 & 1027 & 2-Vinyl-6-methyl-pyrazine & - & 0.34 & 0.30 & 0.54 & - & 0.67 \\
\hline 46 & 1048 & Phenylacetaldehyde & 0.81 & - & 1.25 & 1.68 & 0.72 & - \\
\hline 47 & 1073 & 3-Ethyl-2,5- dimethyl-pyrazine & 0.23 & - & - & 0.60 & - & 0.53 \\
\hline 48 & 1095 & 4-Hydro-3,5-dimethyl-3-(2H)-furanone & 0.34 & - & 0.42 & - & - & - \\
\hline \multicolumn{3}{|r|}{ Total } & 26.57 & 69.36 & 33.82 & 60.29 & 14.87 & 60.50 \\
\hline
\end{tabular}


Table 3. Continued....

\begin{tabular}{|c|c|c|c|c|c|c|c|c|}
\hline \multirow{2}{*}{$\begin{array}{c}\text { Peak } \\
\text { No. }\end{array}$} & \multirow{2}{*}{ (K.I.) } & \multirow{2}{*}{ Compounds } & \multicolumn{6}{|c|}{ TIC (values $\times 10^{6}$ ) } \\
\hline & & & $\mathbf{A s}_{\mathrm{s}}$ & $\mathbf{B}_{\mathrm{s}}$ & $\mathbf{A}_{\mathrm{co}}$ & $\mathbf{B}_{\mathbf{c o}}$ & $\mathbf{A t}_{\mathbf{t}}$ & $\mathbf{B}_{\mathrm{t}}$ \\
\hline \multicolumn{9}{|c|}{ Lipid degradation products } \\
\hline 2 & 621 & 2-Methyl furan & 0.18 & 3.28 & - & - & - & 0.77 \\
\hline 3 & 634 & Tetrahydrofuran & 0.68 & 3.74 & 1.22 & 1.39 & - & - \\
\hline 4 & 635 & 1-Butonol & - & - & 0.48 & 1.40 & - & - \\
\hline 8 & 670 & Pentanal & 0.18 & 0.92 & - & - & - & $\overline{-}$ \\
\hline 9 & 681 & 2-Ethylfuran & 3.81 & 11.27 & - & 8.29 & - & $\overline{-}$ \\
\hline 13 & 747 & 2- Methyl-2-butanal & - & 0.49 & - & 0.75 & - & $\overline{-}$ \\
\hline 14 & 767 & 1-Pentanal & - & 0.14 & - & 0.26 & - & - \\
\hline 15 & 799 & Hexanal & 2.00 & 15.76 & 5.36 & 8.22 & 2.53 & 10.46 \\
\hline 16 & 809 & Butanoic acid & - & - & $\bar{L}$ & 0.69 & - & - \\
\hline 19 & 826 & (E) 2- Ethyl-2-butanal & 0.59 & 0.52 & - & - & 1.95 & 3.28 \\
\hline 22 & 851 & 2-Hexanal (E) & - & - & - & 0.63 & - & - \\
\hline 23 & 881 & Hexanol & - & - & - & - & 2.83 & 5.83 \\
\hline 24 & 882 & 3-Heptanone & - & 0.32 & - & - & - & - \\
\hline 36 & 984 & 1- Octen-3- ol & - & 0.36 & - & 0.64 & $\begin{array}{ll}------- \\
\end{array}$ & 11.17 \\
\hline 37 & 988 & Haxanoic acid & 1.63 & 1.69 & 3.04 & 3.50 & 2.07 & 9.13 \\
\hline 38 & 993 & 2- Pentyl furan & 0.15 & 0.70 & 0.50 & 0.68 & 0.27 & 1.05 \\
\hline 39 & 999 & Octenal & - & - & - & 0.26 & - & - \\
\hline 43 & 1038 & Benzyl alcohol & 0.83 & 1.98 & - & - & - & 4.85 \\
\hline 52 & 1108 & Nonanal & 0.31 & 1.12 & 0.32 & 0.63 & 1.25 & 1.16 \\
\hline 53 & 1192 & Decanal & - & - & - & - & - & 1.06 \\
\hline 57 & 1235 & 2,4 (E,E)Nonadienal & 0.26 & - & - & 0.61 & - & - \\
\hline 58 & 1259 & Nonanoic acid & - & - & - & - & - & 0.54 \\
\hline 59 & 1263 & 2-Decenal & - & - & 0.21 & - & - & - \\
\hline 62 & 1299 & 2,4 Decadienal $(\mathrm{E}, \mathrm{Z})$ & 0.67 & 0.40 & 1.67 & 1.83 & - & 1.00 \\
\hline 63 & 1306 & 2,4 Decadienal $(\mathrm{E}, \mathrm{E})$ & 0.29 & - & 0.75 & 1.36 & 0.55 & 1.09 \\
\hline 65 & 1358 & Octadecanal & 0.18 & - & 0.39 & - & 0.32 & 0.90 \\
\hline 68 & 1370 & Dedcanoic acid & 0.20 & - & 0.41 & 0.41 & 0.53 & 1.48 \\
\hline 69 & 1385 & Ethyl decanoate & 0.27 & 0.52 & - & - & - & - \\
\hline 72 & 1407 & Dodecanal & - & 1.51 & - & - & - & - \\
\hline 76 & 1470 & Dodecanol & 0.16 & 0.55 & 0.32 & 0.76 & 0.44 & 1.18 \\
\hline 78 & 1528 & Methyl decanoate & 0.27 & - & - & - & 0.82 & 1.48 \\
\hline 79 & 1529 & $\alpha$-Decalactone & - & - & 1.25 & 0.88 & - & - \\
\hline 80 & 1547 & $\beta$-Decalactone & - & - & 0.33 & 0.46 & - & - \\
\hline
\end{tabular}


Table.3 Continued...

\begin{tabular}{|c|c|c|c|c|c|c|c|c|}
\hline \multirow{2}{*}{$\begin{array}{c}\text { Peak } \\
\text { No. }\end{array}$} & \multirow{2}{*}{ (K.I.) } & \multirow{2}{*}{ Compounds } & \multicolumn{6}{|c|}{ TIC (values $\times 10^{6}$ ) } \\
\hline & & & $\mathbf{A s}_{\mathrm{s}}$ & $\mathbf{B}_{\mathrm{s}}$ & Aco & $\mathbf{B}_{\mathbf{c o}}$ & $\mathbf{A}_{\mathbf{t}}$ & $\mathbf{B}_{\mathrm{t}}$ \\
\hline \multicolumn{9}{|c|}{ Lipid degradation products } \\
\hline 81 & 1563 & Dodecanoic acid & 0.28 & - & 0.28 & - & - & 1.61 \\
\hline 82 & 1592 & Ethyl dodecanoate & 0.28 & - & 0.51 & 0.93 & 0.33 & 1.62 \\
\hline 83 & 1599 & Hexadecane & 0.10 & 0.64 & - & - & 1.52 & 4.85 \\
\hline 84 & 1680 & Tetradecanol & 2.14 & 1.03 & - & - & 3.93 & 4.80 \\
\hline 85 & 1685 & $\alpha$-Dodecalactone & - & - & 1.83 & 7.29 & - & - \\
\hline 86 & 1700 & Heptadecane & 0.24 & 0.54 & - & - & 0.55 & 2.43 \\
\hline \multicolumn{3}{|r|}{ Total } & 15.70 & 47.48 & 18.87 & 41.87 & 19.89 & 71.74 \\
\hline \multicolumn{9}{|c|}{ Sulfur compounds } \\
\hline 12 & 742 & 1,2-Dimethyl disulfide & 0.32 & 0.41 & - & - & - & - \\
\hline 28 & 896 & Methional & 0.31 & 0.23 & 0.51 & 1.29 & - & 1.03 \\
\hline 34 & 971 & Dimethyltrisulfide & 0.34 & 2.31 & 1.98 & 2.67 & 1.44 & 4.59 \\
\hline 32 & 951 & Methyl-1- propenyl disulfide & - & - & 0.26 & 0.31 & - & - \\
\hline 44 & 1039 & Iso propely propyl disulfide & - & - & 3.32 & 8.86 & - & - \\
\hline 45 & 1040 & Isobutylthiazole & - & - & - & - & 3.86 & 4.85 \\
\hline 51 & 1106 & Dipropyl disulfide & - & - & 0.84 & 1.71 & - & - \\
\hline 67 & 1363 & Dipropyl trisulfide & - & - & 0.54 & 0.96 & - & - \\
\hline \multicolumn{3}{|r|}{ Total } & 0.97 & 2.95 & 7.45 & 15.80 & 5.30 & 10.47 \\
\hline \multicolumn{9}{|c|}{ Trepenes } \\
\hline 42 & 1033 & Limonene & 0.27 & 0.73 & 0.40 & 1.79 & - & 0.46 \\
\hline 50 & 1101 & Phenyl alcohol & - & - & - & - & 0.23 & 1.27 \\
\hline 56 & 1200 & $\alpha$-Terpineol & - & - & - & - & 0.55 & 1.78 \\
\hline 60 & 1264 & Geranial & - & - & - & - & 0.20 & 0.74 \\
\hline 61 & 1271 & Geraneol & - & - & - & - & 0.80 & 0.59 \\
\hline 64 & 1351 & Eugenol & - & - & - & - & 0.42 & 1.26 \\
\hline 71 & 1400 & Methyl eugenol & - & - & - & - & 2.68 & 5.63 \\
\hline 73 & 1453 & Geranylacetone & - & - & - & - & 0.43 & 1.77 \\
\hline 74 & 1459 & $\beta$-(E)farnesene & - & - & - & - & 0.43 & 1.04 \\
\hline 75 & 1464 & Ethyl cinnamate & - & - & - & - & 0.56 & 1.43 \\
\hline 77 & 1500 & $\beta$-Ionone & - & - & - & - & 1.63 & 4.15 \\
\hline \multicolumn{3}{|r|}{ Total } & 0.27 & 0.73 & 0.40 & 1.79 & 7.93 & 20.12 \\
\hline
\end{tabular}


Table 3. Continued....

\begin{tabular}{|c|c|c|c|c|c|c|c|c|}
\hline \multirow{2}{*}{$\begin{array}{c}\text { Peak } \\
\text { No. }\end{array}$} & \multirow{2}{*}{ (K.I.) } & \multirow{2}{*}{ Compounds } & \multicolumn{6}{|c|}{ TIC (values $\times 10^{6}$ ) } \\
\hline & & & $\mathbf{A s}_{\mathrm{s}}$ & $\mathbf{B}_{\mathrm{s}}$ & Aco & $\mathbf{B}_{\mathrm{co}}$ & $\mathbf{A}_{\mathbf{t}}$ & $\mathbf{B}_{\mathrm{t}}$ \\
\hline \multicolumn{9}{|c|}{ Miscellanens compounds } \\
\hline 27 & 893 & Styrene & 0.41 & 0.72 & 0.41 & 0.72 & - & - \\
\hline 49 & 1096 & Guaiacol & - & - & - & - & 0.53 & 2.35 \\
\hline 54 & 1193 & 2-Isobutyl-3-methoxy pyrazine & 2.68 & 2.95 & 0.77 & 0.43 & - & - \\
\hline 55 & 1194 & Methyl salicylate & - & - & - & - & 0.32 & 1.01 \\
\hline 66 & 1359 & $\beta$-Damascenone $(z)$ & - & - & - & - & 0.49 & 1.25 \\
\hline \multicolumn{3}{|c|}{ Total } & 4.23 & 3.96 & 3.86 & 4.10 & 1.75 & 5.68 \\
\hline \multicolumn{3}{|c|}{ Total of all volatiles: } & 47.74 & 124.48 & 64.40 & 123.85 & 49.74 & 168.51 \\
\hline
\end{tabular}

TIC: Total ion chromatogram; KI: Kovats Index

As: Potato chips flavoured with salt (brand A); Bs: Potato chips flavoured with salt (brand B); Aco: Potato chips flavoured with cheese and onion (brand A)

$\mathbf{B}_{\mathrm{co}}$ : Potato chips flavoured with cheese and onion (brand B); At: Potato chips flavoured with tomato (brand A); Bt: Potato chips flavoured with tomato (brand B). 


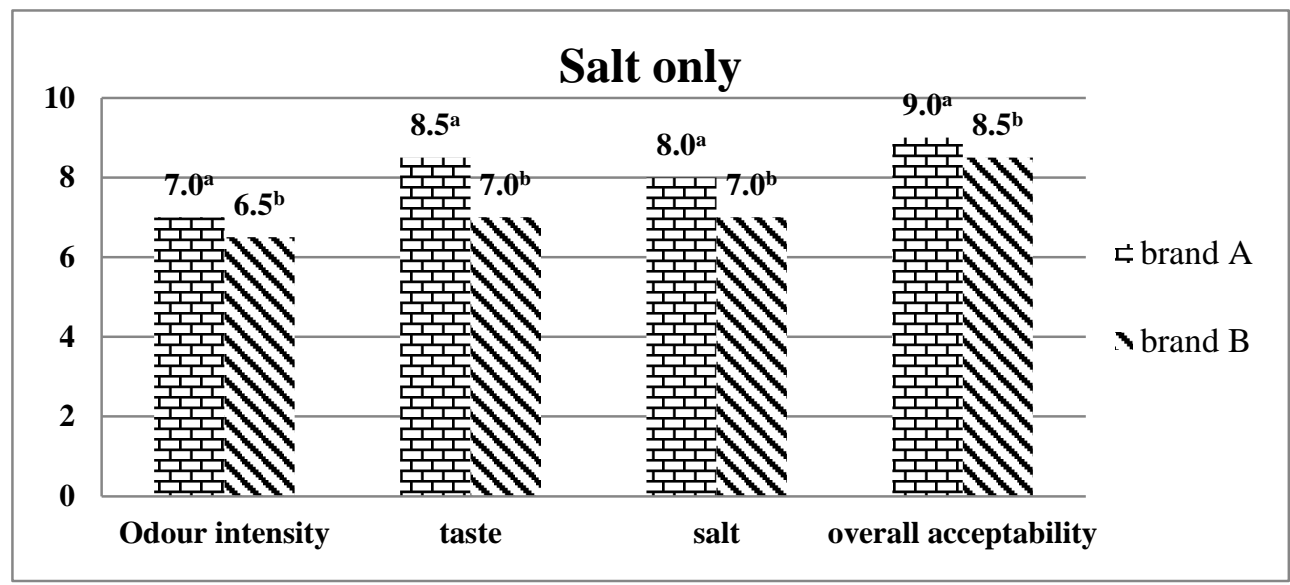

Figure1. Sensory characteristics of flavoured potato chips with salt. For each sensory attribute the values followed by different superscript low case letters are significantly different.

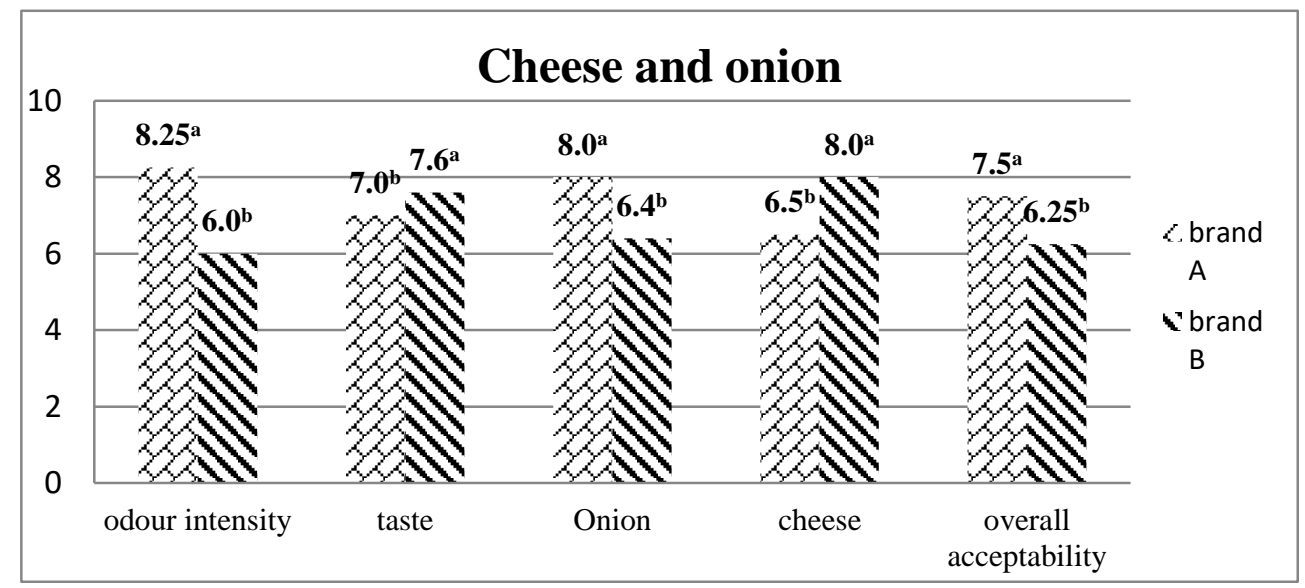

Figure2. Sensory characteristics of cheese and onion seasoned potato chips. For each sensory attribute, the values followed by different superscript low case letters are significantly different.

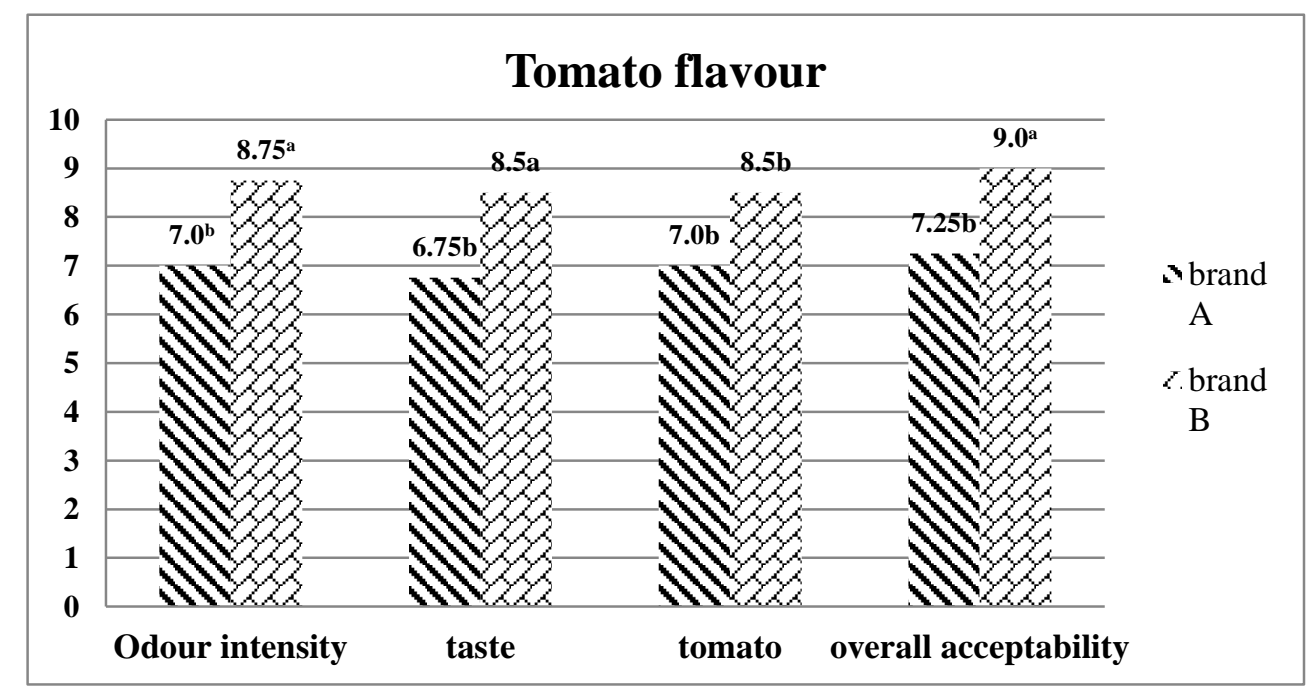

Figure3. Sensory characteristics of tomato seasoned potato chips. For each sensory attribute, the values followed by different superscript low case letters are significantly different. 


\section{دراسة مقارثة على المركبات الطيارة والخصائص الحسية لبعض رقائق البطاطس المنتجة محلياً \\ مصطفى ابو الفضل محمد ${ }^{1}$ ،محد ابراهيم محمد 1، هدى هانم محمد فاضل ²، سامح محمد صلاح غانم 1،"

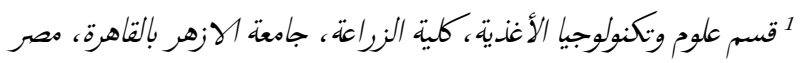

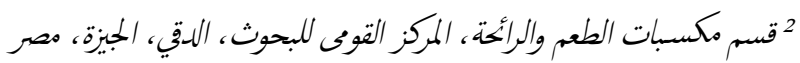
البريد الاليكترونى للباحث الرئيس:sameh.ghanem@azhar.edu.eg الملخص العربي

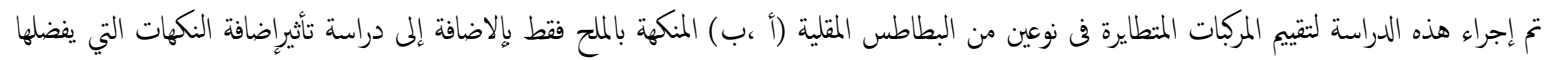

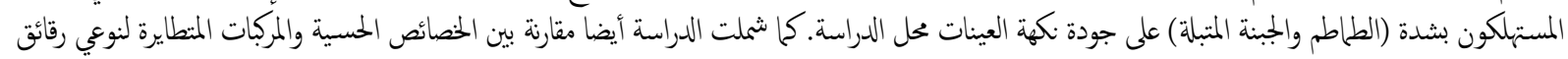

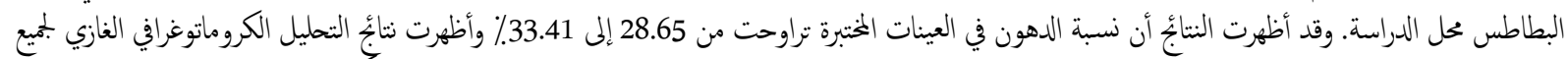

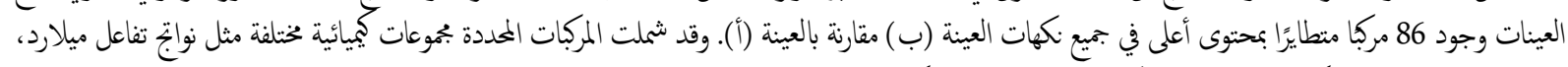

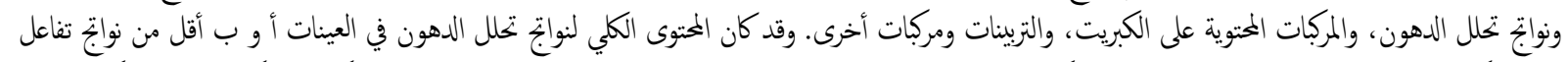

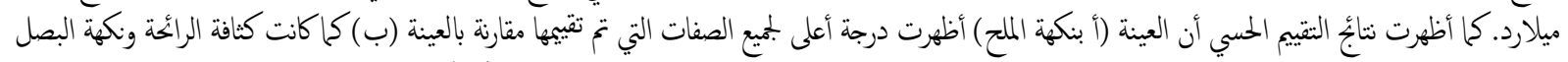

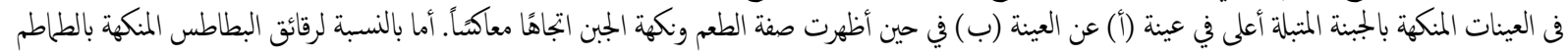

أظهرت العينة (ب) درجة أعلى لمجيع الصفات الحسية مقارنة بالعينة (أ). الكلمات الاسترشادية: رقائق البطاطس، رقائق البطاطس بطعم الملح، الجبنة والبصل، نكهة الطاطم، كثافة الرائحة. 